Special Issue: Simulation and Intelligent Agents to Support Defence and Homeland Security

\title{
Simulating the integration of photovoltaic technology on the modern infantry soldier using Modelling and Simulation: scenarios and guidelines
}

Ioannis Paraskevopoulos ${ }^{1}$, Emmanuel Tsekleves ${ }^{2}$

\begin{abstract}
The operational range and manoeuvrability of the modern infantry soldier is restricted by the overall load and bulk of equipment ranging from 50 to 75 kilos. Today's soldiers rely heavily on batteries to meet their power requirements, which make up for $25 \%$ of the overall load. This results in a significant increase on soldier's physical stress and cognitive burden. Recent developments in renewable energy and more particularly the evolution of very thin and flexible wearable photovoltaic devices provide promising solutions for the application of such technologies on the infantry soldier. However since these flexible substrate devices are still under development or produced at a very small scale their application and use has to be simulated prior to integrating to the infantry soldier. Such simulations need to take into account the specific requirements and different fields of operation of the infantry soldier, in the context of weather, date and time, global location and for different military mission environments. This paper presents a number of simulations performed for a wide range of scenarios in the context of the Solar Soldier project. It discusses the key results, offering a set of guidelines for the positioning and integration of such renewable energy technology on the modern infantry soldier. Moreover, this paper suggests future improvements on the methodology and optimisation of the procedures.
\end{abstract}

Keywords: Renewable energy, photovoltaic, wearable, product integrated, daylight simulation, infantry soldier, military environment, 3D Simulation, Virtual Reality

\section{Introduction}

Despite the modern advances in military technology the infantry soldier continues to play a very significant role in defence. In the age of stealth jets, nuclear munitions and guided weapons, it is still the infantry soldier that examines and secures a location to ascertain whether the target area is cleared and the enemy is defeated. The modern infantry soldier utilises the electronic technology and resources available today, in order to penetrate into

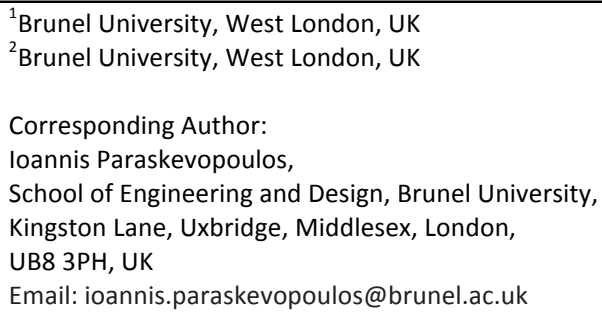


hostile and difficult terrain where armoured vehicles cannot trespass and overcome the enemy. The power requirements of such electronic technology, critically essential for the modern soldier, are much higher when compared to the power requirements of a civilian counterpart. Furthermore, the environment of operation is far more hostile and challenging than those of the civilian applications and the loss of power may endanger the infantry soldier's life. That is the main reason behind the massive overload of batteries constituting the $25 \%$ (source Ministry of Defence, MoD) of the overall equipment load (including lethal, survival and communication). Due to the aforementioned fact, there is an uncontested restriction of manoeuvrability and operational range as well as a significant burden both physical and cognitive.

The recent advances in the field of sustainable energy and particularly the innovative flexible and wearable photovoltaic (PV) technologies could offer a potential solution to this issue, by removing, or reducing at a great extent, the use of batteries. The Solar Soldier project, which is partly funded by the Defence Science and Technology Laboratory (DSTL) of the MoD in the United Kingdom (UK)and the Engineering and Physical Sciences Research Council (EPSRC), investigates this research challenge. Part of this project is the work presented by this article which focuses on how could one integrate the PV technology epitomising the Solar Soldier concept from a human interface and design perspective. The objectives of this challenge are twofold:

- To assess the incorporation of the PV technology on the uniform and equipment of the infantry soldier.

- To measure and evaluate the effectiveness (amount of light captured under various scenarios) and usability (human comfort, intuitiveness) 
The bounds of this paper include and present the study of the second objective with a focus on the effectiveness of the proposed system. The usability of the device is examined by liaising and interacting with the Infantry Trials and Development Unit (ITDU) of the DSTL in order to acquire more in depth knowledge on the casualties and motional habits of infantrymen during military operations. The effectiveness of the device is measured by employing the use of virtual simulations and more particularly by using a virtual framework of Modeling and Simulation (M\&S).

The article is organised in a number of sections. Section 2 offers a background literature review on the relevant aspects. This is followed by the presentation of the adopted methods. Lastly the outcomes of the simulations and the inferred conclusions on the design aspects of the incorporation of PV into the Solar Soldier are presented.

\section{Background}

The theoretical background of the study presented in this paper falls within various research areas such as modelling and simulation (M\&S), virtual reality (VR) applications and product design aspects.

\subsection{Virtual Reality and Defence applications}

The advances of virtual reality (VR), in recent years, have led to the development of new areas of applications beyond the entertainment industry. Research and development in interactive VR has been employed in the areas of training, education, health and simulation with one of the major areas of interest being military and defence applications ${ }^{1}$. VR can be utilised for military applications to perform a wide range of simulations. These range from cognitive and behaviour simulations in battle to ergonomic simulations; all serving the improvement of the 
welfare of the modern soldier. These simulations have to be conducted in a virtual framework often consisting of assets that offer 3D graphical representations of terrains, human avatars and objects as well as weather and daylight augmented systems. All these elements create a Virtual World on a computer-based simulated environment. This is of significant interest and importance to research, as it offers a very useful alternative reality especially for situations such as this where actual experiments are not feasible or dangerous to conduct in real life ${ }^{2,3}$. More precisely, Chrysolouris et $\mathrm{al}^{4}$ have conducted research in the area of human ergonomics in assembly line and Reece ${ }^{5}$ has studied the movement behaviour of soldier agents on a virtual battlefield. Furthermore the Santos ${ }^{6,7}$ project offers a virtual platform for human ergonomics in military environments and Shiau and Liang ${ }^{8}$ present a real-time network VR military simulation system comprising weather, physics and network communications. Blount ${ }^{9}$ has introduced the aspect of physical fitness into simulations for infantry soldiers and others such as Cioppa, Lucas and Sanchez ${ }^{10}$ and Bitinas, Henscheid and Truong ${ }^{11}$ have worked with agent-based simulations and their military applications, focusing on human factors in military combat and non-combat situations respectively. Apart from these aforementioned articles, there is a recently published three-volume edition containing an extensive literature on virtual reality and applications: "The PSI Handbook of Virtual Environment Training and Education: Developments for the Military and Beyond"12. The second volume of this text contains subjects as "Mixed and augmented reality for training", "Evaluating virtual environment component technologies" and "Enhancing virtual environments to support training". The aforementioned literature focuses mainly on simulating human factors and ergonomics either in the production line or in military environments. However the applications of VR human centred simulations are not restricted to 
ergonomics. The aspect of Human Centred Design (HCD) that this article examines is the integration of renewable energy devices on the human vesture and in particular the integration of PV on the uniform or equipment of the modern infantry soldier in terms of light capture efficiency.

\subsection{Simulation of Solar light harvesting}

Currently the main focus of PV technology and its corresponding simulations has been on building and infrastructure applications. The very recent developments in the area of PV devices ${ }^{13,14}$ along with the introduction of thin films and flexible materials for light absorption ${ }^{15}$ have attracted the focus of harvesting renewable energy to human centred applications as well. The study of the performance of the so-called Product Integrated PhotoVoltaics (PIPV) ${ }^{16}$ is twofold. Firstly, to investigate the performance and electrical characteristics of the PV device itself; secondly to study the effectiveness of light harvesting, which is also the main focus and aim of our work. The effectiveness of light harvesting depends on the interaction of the device with the environment as well as on the type of integration of the PV on the product (e.g. attached on clothing, embroidered or woven onto the fabric). The environmental conditions would require the modelling of daylight and shading in a 3D authoring and simulation tool, whilst the integration guidelines would require simulated scenarios and results that would infer the most effective method of integration.

\subsubsection{Daylight and shading modelling}

With regards to daylight modelling there have been numerous studies on methods to maximise solar system outputs ${ }^{17}$. Moreover, there are studies on the shading effect of the environment, 
which investigate the effects of random shading on PV energy production ${ }^{18,19}$. Apart from research studies there has been major development in the corresponding software industry with very intelligent and complex packages developed for daylight simulations, including 3D Studio Max Design by Autodesk (3DSMD), which is the software utilised in this project. 3DSMD was chosen mainly because it comprises a toolset for animation and because it includes the feature of light analysis of a 3D scene, which is essential for a HCD project such as this. 3DSMD also offers extension capabilities through its embedded programming language, Maxscript. It can thus be used to semi-automate the procedures as described in the work of Paraskevopoulos and Tsekleves ${ }^{20}$. The results of the light analysis of 3DSMD have been validated by Reinhart et $\mathrm{al}^{21}$ and Paraskevopoulos and Tsekleves ${ }^{20}$ and the software has been used in a number of other studies regarding light harvesting for PV ${ }^{16,22}$. Nevertheless, all of them have focused on simulations where the PIPV device was in a static position and none of these has used simulation to analyze the effects of movement on PIPV light harvesting. Furthermore no previous work has offered any conclusions or guidelines on the design aspects of wearable PVs in terms of light capturing efficiency of mobile agents.

\subsubsection{Integration of PV on commercial products}

Although the integration of PV on commercial products is not a new idea, the emergence of flexible and thin film materials has extended the possibilities of integration into more products with a smaller scale factor which can be portable. However, until recently and as stated in the work of Mestre and Diehl ${ }^{23}$ there have been no guidelines for the integration of PV on products in the context of either human comfort or efficiency of energy harvesting. The work of 
Reinders ${ }^{24}$ examines in depth the options for PV systems and portable devices and presents their advantages and drawbacks. Among the drawbacks one indicates the lack of PV technology penetration in our society and market. This is mainly due to limited knowledge of this technology by product designers and manufacturers, restricting in turn the extension of applications for this technology. Our work presented in this article aims to fill in this gap by deploying design guidelines and a simulation platform on the integration of PV on military garment or equipment initially and commercial products in the future. As already mentioned in the introduction of this article the use of virtual reality simulations is a prerequisite for military applications due to the hostile and extremely hazardous environment. Randal et $\mathrm{al}^{25}$ have integrated solar modules to use them as light sensors in order to collect physical measurements and not for the purposes of light analysis simulation. With regards to the design aspects of the integration of PV on clothing Schubert and Werner ${ }^{26}$ have presented an overview of flexible solar cell technologies applied on wearable renewable sources. This however focuses only on the material aspect of PV. In their paper Schubert and Werner ${ }^{26}$ reference Gemmer, who has performed experimental investigation on light harvesting under different daylight scenarios and has calculated energy yield for various user profiles, for example a "regular clerk", an "outdoor construction worker" and a "night shift nurse". In the system we propose these profiles can be very easily modelled (3D avatars and motion capture) and simulated (light analysis tool, 3DSMD) for all various light conditions (daylight system, 3DSMD) and encompassing environments (3D terrain models). The outcomes of such simulations would infer the design guidelines of the most efficient manner of integration of PV on clothing in terms of light harvest. 


\section{Methodology}

The objectives presented in the Introduction, necessitated the employment of a virtual framework able to conduct a number of experiments and collect measurements, which are impossible to collect due to the hazardous nature of the real environment. The methodology that fulfils the development of such a virtual framework is Modelling and Simulation (M\&S) ${ }^{27}$. The application of M\&S presented in this article is aimed at applying an existing feature of a 3D authoring commercial software, 3DSMD, by extending its capabilities and applying it to simulation of daylight for sustainable energy applications of military interest. The lighting analysis system of 3DSMD will be employed in a virtual military environment framework. The light sensors employed as design assets by the software are attached on specific areas of the soldier's uniform and equipment to assess the incorporation of PV technology. Figure 1 illustrates the overall adopted methodology:

\section{Modelling}
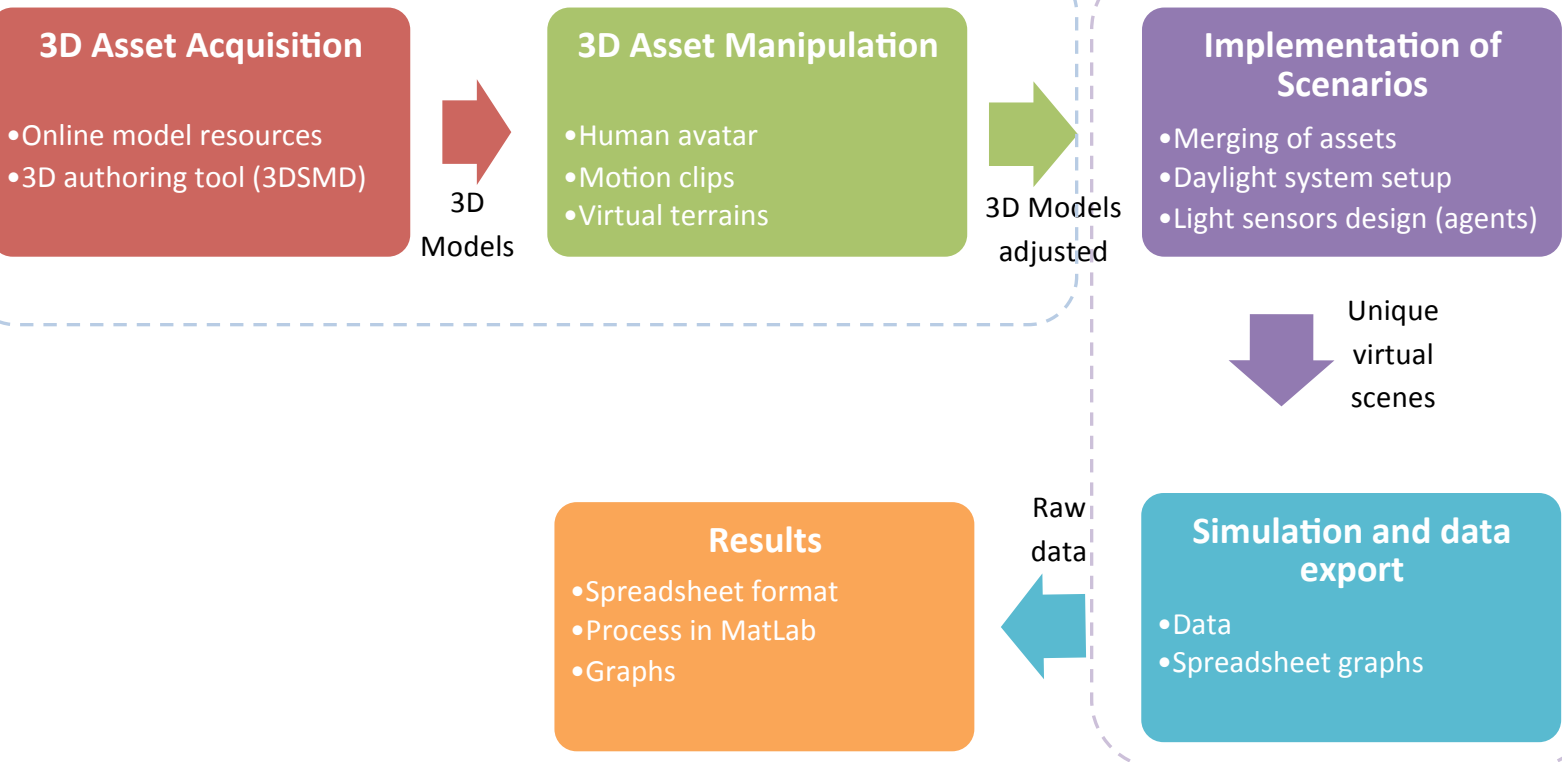

Simulation and data export

-Data

-Spreadsheet graphs 
The initial stage of the methodology is to acquire all virtual assets required for the scope of the modelling and then the second stage includes the manipulation of these 3D assets together. In the 3D asset manipulation stage a human avatar (British army infantry soldier), a set of animation clips (motion capture) and virtual terrains (forest scene, urban area, military camp) are included. These have to be manipulated (modelling, scaling, texturing, animating) in order to fulfil the requirements of the planned simulation scenarios. Then all the assets are merged together. The 3DSMD daylight system is set up and the light sensors are designed. This completes the virtual scenes ready for simulation. The simulations output raw data in comma separated value (CSV) form, which then can be easily transformed to spreadsheets and imported to Matlab for further analysis and presentation.

\subsection{Modelling}

The final outcome of the modelling process is a virtual military framework that includes a range of virtual terrains, a human avatar and a range of movements (animated clips) combined together to form each unique military scenario presented in this paper.

The modelling process involved several stage, as depicted in Figure 1 . In the first stage, the models required for the various scenarios are developed or acquired through online 3D resources. After all assets have been selected, the separate models of the human avatar and terrain models are manipulated and merged into unique scenes along with the daylight system and the other assets (virtual sensors and animation clips) to form the unique scenarios. Some additional amendments are performed on the models to ensure compliance with the requirements of the lighting analysis plug-in of 3DSMD, which are discussed below: 


\section{a. The Lighting system}

The lighting system utilised for the purposes of this paper is the daylight system of 3DSMD. The daylight system allows the designer to select the date and time as well as the location on the globe through a selection of cities or latitude andlongitude value pairs. Furthermore, it provides users the ability to adjust the sky model by choosing one of the three following options: the Haze-driven model, the Perez "All weather model" and the Commision Internationale de I'Eclairage (CIE)model. The CIE sky supports only the extreme cases of overcast and clear sky ${ }^{28}$ whilst the Perez "All weather model" ${ }^{29}$ supports intermediate cases also. Thus, when the weather data are available, it is more appropriate to use the Perez "All weather model", whilst when relying on typical light intensity values CIE offers a more suitable solution. The sky model $^{30,31}$ chosen for this case was the Perez "All weather model". This is provided online by Autodesk, and allows its user to employ the irradiance data provided by Photovoltaic Geographical Information System (PVGIS) ${ }^{32}$. PVGIS is an online system developed by the Joint Research centre for Energy and Renewable Energy Units. Among the data available online, there are specific areas that are of major military interest and thus very valuable for the purposes of this study. The data utilised include a set of average daily irradiance variations for the chosen location with time intervals as low as 15 minutes during a typical day of any given month. This approach covers a wider range of variable climates.

b. Rescale of the Analysis Value colour coding

The lighting analysis tool provides the user with an Image overlay to the light meters with a coloured coded scale. The colour coding uses blue for zero and red for the maximum value set 
by the designer. In our application and since it is an outdoor illuminance analysis, we use the typical outdoor maximum illuminance value for a clear sky which corresponds to 120,000 lux $^{33}$.

\section{c. The Lighting analysis Render settings}

The render setting of the lighting analysis are as complex and varying as most of rendering setting for any other 3D application. Fortunately, the Exposure ${ }^{\mathrm{TM}}$ plug-in comes with a render preset and therefore there is no necessity of adjusting manually those complex parameters.

\section{d. Materials}

The number of the different material types used in our case is due to the complexity of the outdoor scenes and the high detail of both the terrain models and the human avatar. Listing each material with the corresponding properties is out of the scope of the paper.

The approach adopted for the materials accommodates realistic textures mapped on the 3D objects and optical properties that match the typical optical properties for the specific type of any given object. The reflectivity or transmissivity values for the virtual objects are selected according to the Illuminating Engineering Society (IESNA) standard values for building materials ${ }^{34}$. The typical wall reflectivity applied is 0.7 , floor reflectivity is set to 0.3 , ground reflectivity (albedo) to 0.2 and window transmissivity to 0.77 (single glazing) all according to IESNA standards ${ }^{35}$. The Exposure plug-in confines the use of material libraries only to Arch \& Design and Pro-materials. Hence, the materials used for the scene setup consist of Arch \& Design materials with diffuse and bump maps from libraries of the 3D models adjusted to the aforementioned optical properties. Another strategy that could be adopted but is very demanding in terms of equipment, is the actual measurement of the optical parameters of the objects and the input of those in the virtual lighting analysis tool. The measurements of 
reflectivity and transmissivity of the actual objects would lead to qualitative results and it is highly recommended when there is access to the actual correspondent object of a virtual 3D model plus access to special equipment like a spectrophotometer. The experimental validation of the lighting analysis plug-in of 3DSMD employs such an approach as the authors of the study measured the optical properties of the original room and objects they modelled in the 3D authoring engine ${ }^{21}$.

The embedded light analysis tool of 3DSMD does not incorporate a feature for analysing mobile light sensors as the main application of light analysis is in the area of building engineering. For that reason, we developed a script to perform an analysis for virtual scenes containing mobile objects such as the human avatar, in our case. The script exports light data with a sample rate that the user can choose. For instance for an animation with a default frame rate of 30 frames per second (fps) and a total of 3000 frames ( 1 minute and 40 seconds), the user can set the sample rate of analysis to 1 second. In this case the analysed frames will be every 30 frames resulting to 100 measurements. The measurements are then exported by the same script to spreadsheet format and imported to Matlab for further analysis. Therefore, in our approach we utilise a commercially available 3D authoring tool and extend it by using its own programming interface and employ an M\&S methodology to an application of military interest. This methodology enables our study to be the first one to analyse mobile light sensors in a virtual environment.

\subsection{The Simulation}


After the modelling of the environment and merging with the other virtual elements, the simulation procedure is enabled. Apart from the 3D models, every scene comprises virtual light sensors attached on various areas of the soldier's uniform. These virtual sensors are the designed light sensors. The distribution and positioning of the light sensors on the uniform are based on suggestions and recommendations after liaising with the corresponding expert of DSTL. It should be noted that the total number of light sensors to be used in a simulation is restricted (this is typically 8 for most high end computers) due to the high computing power requirements of the simulated scenarios. Figure 2 and Figure 3 depict the positioning of the selected light sensors on the soldier's uniform and helmet:

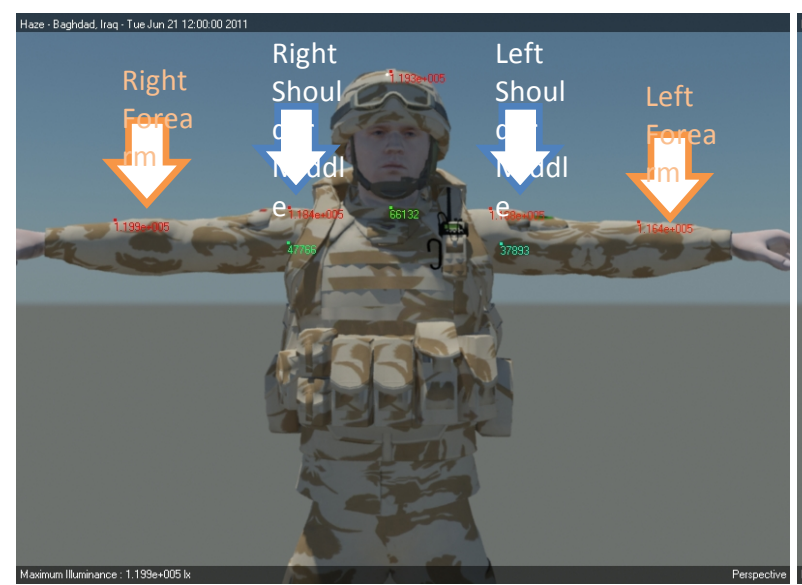

Figure 2 Distribution of light sensors (front view)

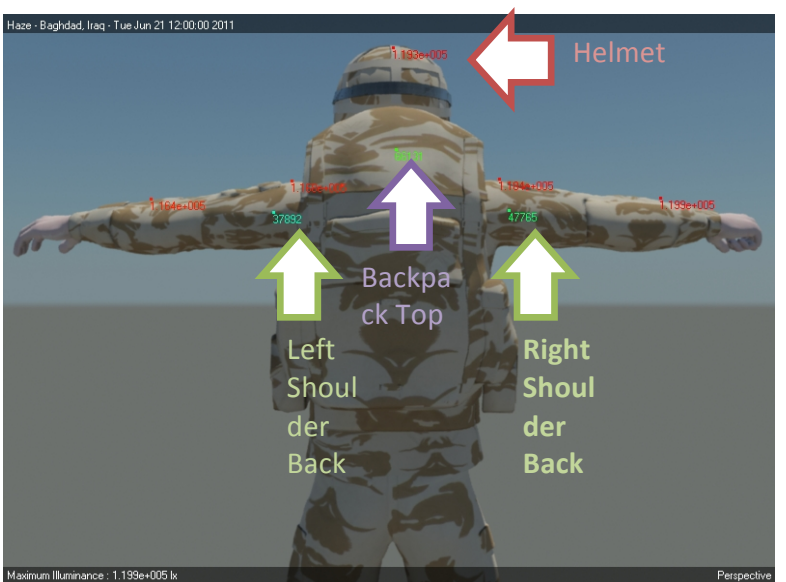

Figure 3 Distribution of light sensors (back view)

Eight light sensors comprise the collection of sensors, namely:

- Right Shoulder Middle

- Left Shoulder Middle

- Right Shoulder Back

- Left Shoulder Back

- Right Forearm

- Left Forearm

- Helmet

- Backpack Top 
These light sensors are attached on the geometry of the human avatar, thus they follow every movement their parent geometry performs. Several 3D models have been employed for the purposes of our simulation. These can be listed as follows:

- Terrain:

- Urban area (Arab city model)

- Forest scene (Pine creek model)

- Military camp (Base model)

- Human Model:

- Infantry soldier - desert camouflage (Royal Anglian Desert model)

- Infantry soldier - woodland camouflage (Royal Anglian woodland model)

Merging the models from these two categories result in complete scenes which include a human model and a terrain. According to the daylight system adjustments presented earlier the 3DSMD daylight system is then employed. This system consists of a sun and a compass that is used to calibrate the global position of the scene. After the design of the solar system the scene is ready to be animated. For the purposes of this study, the animation clips selected was that of a walk-cycle, as the effect of each parameter is to be analysed one at a time. The walk-cycle is one of the most typical motions that a dismounted infantry soldier performs on average in most missions. Thus, in the boundaries of this study only the effects of different time, date and global location on specific landscapes ( 3 case studies) and specific movement style (simple walk cycle) are to be examined. The global locations to examine are also limitless. Since the work conducted is part of a military project of the British Royal Army, a few locations of interest for the purposes of the project were selected. 


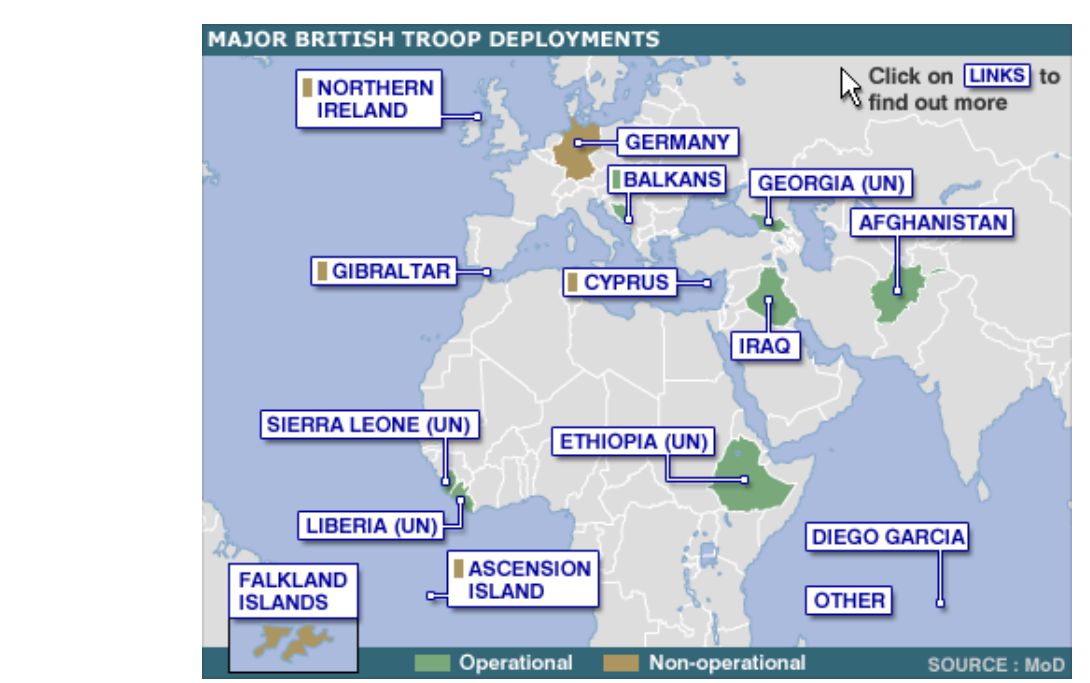

Figure 4 Major british troops deployments (Source: British Broadcasting Corporation)

Figure 4 illustrates the major deployments of British soldiers around the world. The choice of locations to examine covers various latitude and longitude ranges. Thus, the following strategic points of interest are chosen, which offer distinct locations in terms of both longitude and latitude:

- U.K., Catterick Garrison Headquarters, N. Yorkshire $(54.375,-1.708)$

- Kosovo, Pristina $(42.5,20.9)$

- Iraq, Baghdad $(33.33,44.44)$

The methodology of constructing a complete virtual environment for lighting analysis that consists of a terrain, a human avatar, animation clips and a daylight system relies on merging the single 3D models to one scene and adjusting the parameters according to the above standards. The resulted scenes must be simulated in such a manner that they would cover a wide range of times and dates. It must be noted that these types of simulations require high computational time and power due to their high complexity.

The range of times would have to cover most of the effective time in the day in terms of lighting; that is some hours before and some hours after midday. The dates would have to cover all seasons at least. Therefore, the proposed dates and times under examination are: 
- Time:

○ 10.00

○ 12.00

○ 14.00

○ 16.00

- Date:

- Winter (07 Jan)

- Spring (16 Apr)

- Summer (08 Jul)

- Autumn (26 Oct)

The dates themselves are random but the months are one every four and each from every season. Moving on, as mentioned in the modelling chapter above, the sky system employed is the Perez "All weather model" as it accommodates intermediate cases between overcast and clear sky. The 3D software, 3DSMD, requires an input value of light intensity for the simulation and analysis of light in a virtual scene employing a Perez sky model. Thus, the input of solar data is required. These can be taken from existing relevant online sources. As mentioned above the PVGIS project offers valid data online. It covers only the European and Africa continents. They do however cover the requirements of this study. The online calculator provides the user with monthly average solar irradiance values for a given slope. The measurements required for this paper must be in taken with the panels in 0 degrees as we do not want to test conventional photovoltaic panels but we need the solar irradiance as the input for our virtual scene. The irradiance data is measured according to the international system (S.I.) with watt per square meter $\left(\mathrm{W} / \mathrm{m}^{2}\right)$. The software uses illuminance values which are expressed in $\mathrm{Im} / \mathrm{m}^{2}$ or lux. The conversion of $\mathrm{W} / \mathrm{m}^{2}$ to $\mathrm{Im} / \mathrm{m}^{2}$ is a very complicated and circuitous mathematical procedure that requires the engineer to know the spectral composition of the source in order to solve the conversion formula. A publication in the scientific disciple of horticulture, conducted by Thimijan and Heins ${ }^{35}$ provides a table with measured and solved conversion factors for different 
sources including the sun for various spectrum portions. The conversion factor according to these tables is $0.00804 \mathrm{~W} / \mathrm{lm}$. Thus, the interconversion of radiometric to photometric units enables the simulation with typical monthly average irradiance values as input.

The data can be easily extracted by the tool provided by PVGIS ${ }^{1}$ online, then converted with the factor mentioned above and finally organised in tables. For the different locations we have the following results:

Table 1 U.K., Catterick Garrison Headquarters, N.Yorkshire (54.375, -1.708). Light intensity in Lux

\begin{tabular}{|c|c|c|c|c|c|}
\hline & \multirow{3}{*}{$\begin{array}{c}10: 00 \\
6952.2\end{array}$} & \multirow{3}{*}{$\begin{array}{c}12: 00 \\
8582.0\end{array}$} & \multirow{3}{*}{$\begin{array}{c}14: 00 \\
6965.2\end{array}$} & \multirow{3}{*}{$\begin{array}{c}16: 00 \\
1990.0\end{array}$} \\
\hline & & & & & \\
\hline \multirow{2}{*}{ 07_Jan } & Diffuse $^{1}$ & & & & \\
\hline & Beam $^{1}$ & 3358.2 & 5597.0 & 3358.2 & 250.0 \\
\hline \multirow{2}{*}{ 16_Apr } & Diffuse & 22823.3 & 23880.6 & 22823.3 & 18470.1 \\
\hline & Beam & 22388.0 & 26119.4 & 22388.0 & 12686.6 \\
\hline \multirow{2}{*}{ 08_Jul } & Diffuse & 27674.1 & 28358.2 & 27674.1 & 24253.73 \\
\hline & Beam & 27674.1 & 31343.3 & 27674.1 & 17972.6 \\
\hline \multirow{2}{*}{ 26_Oct } & Diffuse & 13992.5 & 15671.6 & 13992.5 & 8022.4 \\
\hline & Beam & 10820.8 & 14303.5 & 10820.8 & 2985.1 \\
\hline
\end{tabular}

Table 2 Kosovo, Pristina $(42.5,20.9)$. Light intensity in Lux

\begin{tabular}{|c|c|c|c|c|c|}
\cline { 3 - 6 } \multicolumn{2}{c|}{} & $10: 00$ & $12: 00$ & $14: 00$ & $16: 00$ \\
\hline \multirow{2}{*}{ 07_Jan } & Diffuse & 13557.2 & 15422.9 & 13557.2 & 6592.0 \\
\cline { 2 - 6 } & Beam & 11442.8 & 15298.5 & 11442.8 & 2176.6 \\
\hline \multirow{2}{*}{ 16_Apr } & Diffuse & 23368.1 & 26990.0 & 23368.1 & 21766.1 \\
\cline { 2 - 6 } & Beam & 33519.9 & 39303.5 & 33519.9 & 18532.3 \\
\hline \multirow{2}{*}{ 08_Jul } & Diffuse & 27798.5 & 27985.1 & 27798.5 & 24502.5 \\
\cline { 2 - 6 } & Beam & 52114.4 & 59701.5 & 52114.4 & 32089.6 \\
\hline \multirow{2}{*}{ 26_Oct } & Diffuse & 18781.0 & 20273.6 & 18781.0 & 12313.4 \\
\cline { 2 - 6 } & Beam & 25373.1 & 31592.0 & 25373.1 & 9639.3 \\
\hline
\end{tabular}

Table 3 Iraq, Baghdad (33.33, 44.444). Light intensity in Lux

\begin{tabular}{|c|c|c|c|c|c|}
\cline { 3 - 6 } \multicolumn{2}{c|}{ 07_Jan } & $\mathbf{1 0 : 0 0}$ & $\mathbf{1 2 : 0 0}$ & $\mathbf{1 4 : 0 0}$ & $\mathbf{1 6 : 0 0}$ \\
\cline { 2 - 6 } & Diffuse & 18532.3 & 20398.0 & 18532.3 & 10012.4 \\
\hline \multirow{2}{*}{ 16_Apr } & Beam & 17786.0 & 23258.7 & 17786.0 & 4664.1 \\
\cline { 2 - 6 } & Diffuse & 27611.9 & 28233.8 & 27611.9 & 22450.2 \\
\hline \multirow{2}{*}{ 08_Jul } & Beam & 43159.2 & 51492.5 & 43159.2 & 22077.1 \\
\cline { 2 - 6 } & Diffuse & 28171.6 & 28607.0 & 28171.6 & 24129.3 \\
\hline \multirow{2}{*}{ 26_Oct } & Beam & 57524.9 & 67288.6 & 57524.9 & 32388.3 \\
\cline { 2 - 6 } & Diffuse & 22761.1 & 24253.7 & 22761.1 & 15422.9 \\
\cline { 2 - 6 } & Beam & 34519.9 & 43283.6 & 34519.9 & 13059.7 \\
\hline
\end{tabular}

\footnotetext{
${ }^{1}$ For more info see: http://re.jrc.ec.europa.eu/pvgis/index.htm
} 
These are the average values for the given days and times for these specific locations. These average monthly measurements only indicate the irradiance value of the given location on a specific date and time. Therefore, the units of the simulated results conform to the units of the input values of the simulation. This study approach can derive a set of guidelines of PV integration on military garment and equipment to be used by the PIPV designers and practitioners. How close these values get, can only be validated by a comparison of actual light intensity measurements and simulated light intensity measurements of a mobile (animated) virtual light sensor in a virtual scene shed with the same light intensity as the real environment. The derived simulation scenarios after all the configurations and setup are described by the following map (Figure 5):

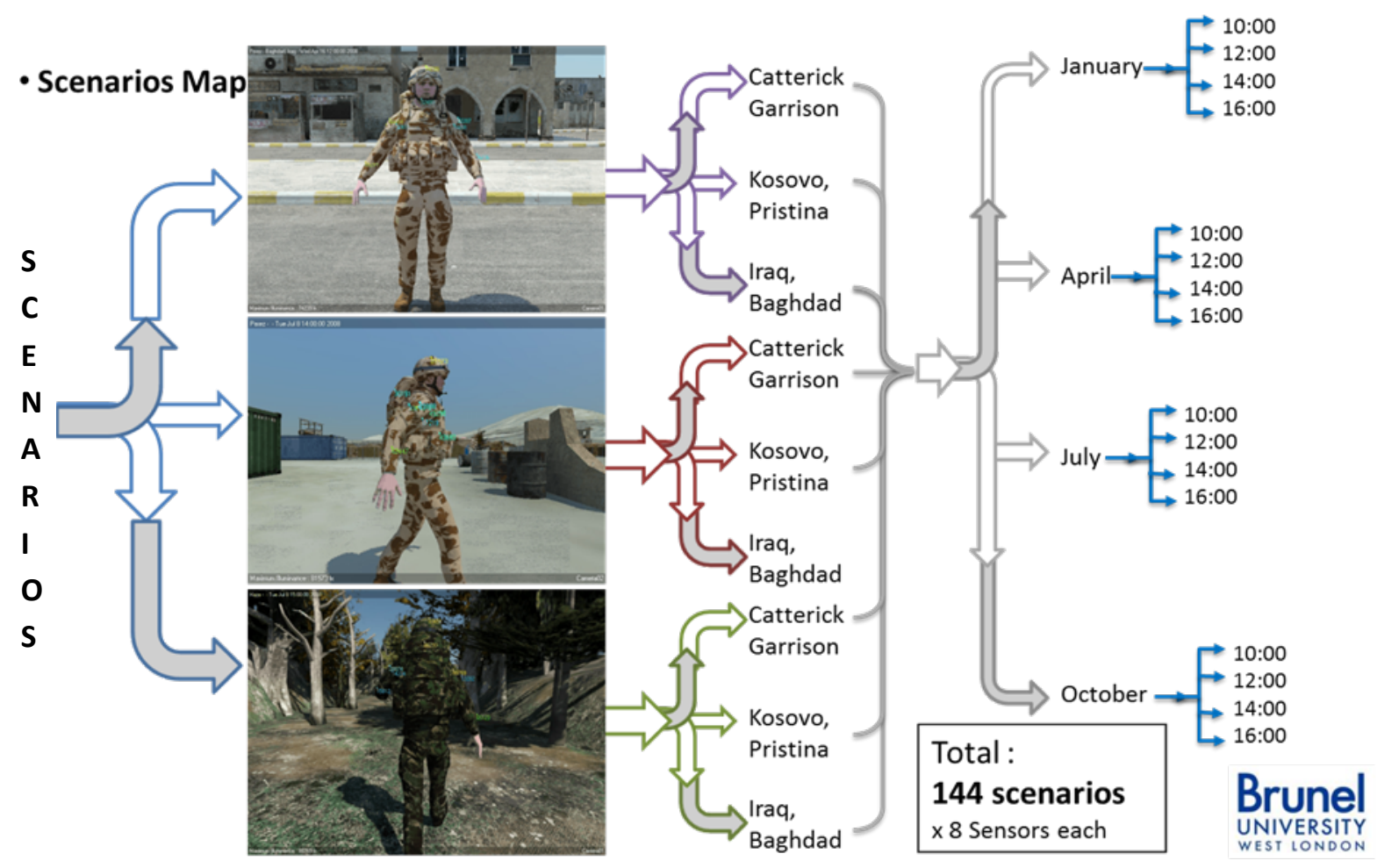

Figure 5 The scenarios map 
The differences of each terrain development imply various walking distance and angles, although a general rule was followed; to animate a walk route of a block in order to cover all orientations. The three route distances vary from $1 \mathrm{~min}$ and $8 \mathrm{sec}$ (forest scene) to 1 minute and 22 seconds (urban area scene). An example of the orientation of the walk cycles is illustrated on the next figure (Figure 6):

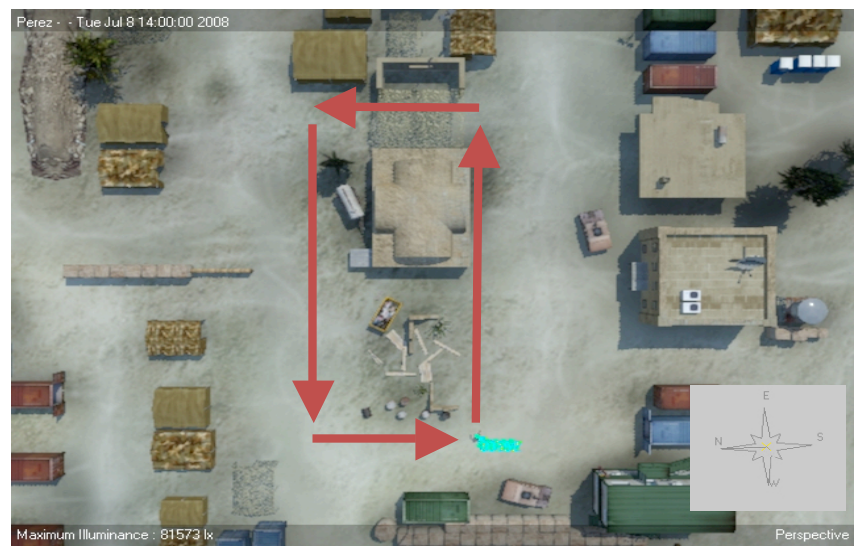

Figure 6 Military scene orientation

The frame rate for the animation was the default value of 30 frames per second. For reasons of computational economy, the sample rate of the light analysis script described above was set to 2 seconds. With all these conditions every simulation cycle lasted about 1 hour. With all these conditions each simulation cycle lasted about an hour on a desktop personal computer with an i5 processor and 4 gigabytes memory..

The average values of each scenario have to be stratified and arranged in increasing order so that a general guideline is established and can be used as future reference by wearable PV designers and engineers. This would form a guide for PV system design stakeholders who wish to position similar devices on other wearable products on human users. In order to accomplish that, we utilise MatLab and its data manipulation and graphical plotting toolsets. MatLab was 
chosen for its high performance and automation features that simplify the manipulation of such massive sets of data.

\section{Results}

As described above, the aim of this study is to simulate the use of PIPV technology based on different military environments and under different light conditions and to investigate the integration of this technology on the uniform of the modern infantry soldier. These simulations will manifest the classification of the various areas on the uniform and equipment in the context of higher light intensity incident on these areas. Engineers and designers can then, by using the data of this study, have a draft blueprint of how and where to incorporate the PV device on the soldier's uniform and equipment. The results are organised in two sets of graphs; one contrasting the seasons and one contrasting the locations. There are a total of 144 scenarios simulated with 8 sensors each. As it is not possible to include all graphs within the paper only a case is presented as single graph and the rest are organised in groups and presented in Table 4. The results, acquired by the helmet sensor in an urban area scene on the $26^{\text {th }}$ of October and for all locations (Baghdad, Pristina, Catterick Garrison), are illustrated in the next figure (Figure 7): 

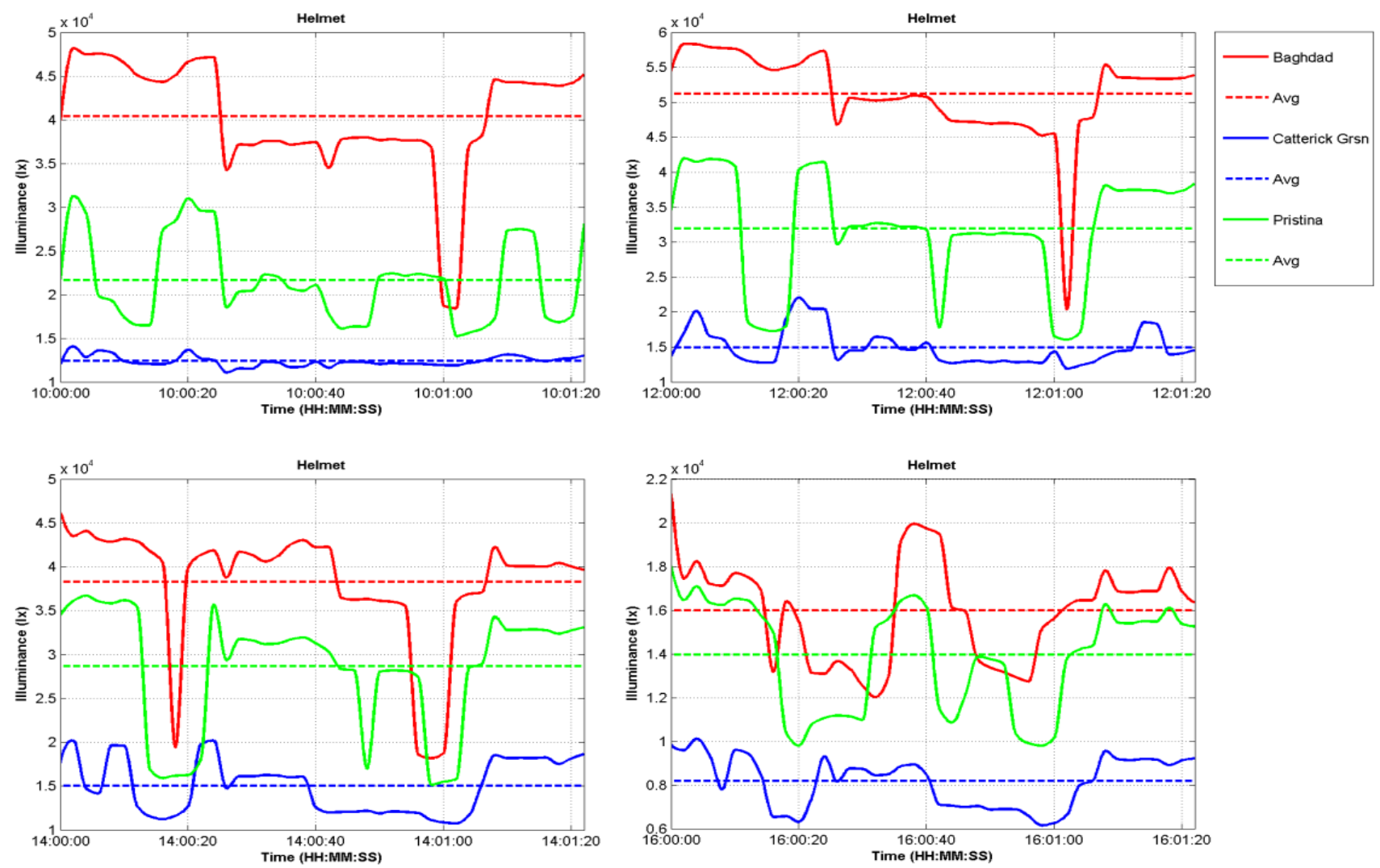

Figure 7 Helmet sensor, $26^{\text {th }}$ October, Urban area scene

This figure consists of four plots one for each time of day. Every plot consists of six graphs, one for each location and their corresponding average values (see legend). The fluctuations of the graphs are due to the change of orientation of the walk cycle the virtual avatar performs as well as the shading effect of the interaction of the avatar with the virtual environment. The most significant element in that set of results is the average value that describes the quantity of light that will be harvested by the point under investigation, in this case the top of the helmet. This value is the most important as a reference of how much light can a specific area on the avatar absorb during a normal walk cycle and under the specifications described in the methodology. That value can be used as a guide by engineers who wish to design a system as independent as possible from current bulky and unwieldy energy storage systems. The average values for each case are organised and presented in figures $1 \mathrm{~A}-9 \mathrm{~A}$ in the Appendix, in a manner that allows the 
comparison and stratification of the selected light sensors, as to which are the most important areas for light absorption. Afterwards, the results are interpreted and the classification of the sensors can be inferred by contrasting their average values by seasons and locations for each environment. The contrast of season and location parameters is presented in Table 4 below (in descending order):

\begin{tabular}{|c|c|c|c|}
\hline & \multicolumn{3}{|c|}{ Scene } \\
\hline \multirow[t]{2}{*}{ Location } & Forest Scene & Military Base & Urban Area \\
\hline & January/April/July/October & January/April/July/October & January/April/July/October \\
\hline Baghdad & $\begin{array}{ll}\text { 1. } & \text { Helmet } \\
\text { 2. } & \text { Forearms } \\
\text { 3. } & \text { Backpack } \\
\text { 4. } & \text { Shoulders Middle } \\
\text { 5. } & \text { Shoulders Back } \\
\end{array}$ & $\begin{array}{ll}\text { 1. } & \text { Helmet } \\
\text { 2. } & \text { Forearms } \\
\text { 3. } & \text { Backpack } \\
\text { 4. } & \text { Shoulders Back } \\
\text { 5. } & \text { Shoulders Middle }\end{array}$ & $\begin{array}{ll}\text { 1. } & \text { Helmet } \\
\text { 2. } & \text { Shoulders Middle } \\
\text { 3. } & \text { Forearms } \\
\text { 4. } & \text { Backpack } \\
\text { 5. } & \text { Shoulders Back } \\
\end{array}$ \\
\hline $\begin{array}{l}\text { Catterick } \\
\text { Garrison }\end{array}$ & $\begin{array}{ll}\text { 1. } & \text { Helmet } \\
\text { 2. } & \text { Forearms } \\
\text { 3. } & \text { Backpack } \\
\text { 4. } & \text { Shoulders Middle } \\
\text { 5. } & \text { Shoulders Back }\end{array}$ & $\begin{array}{ll}\text { 1. } & \text { Helmet } \\
\text { 2. } & \text { Forearms } \\
\text { 3. } & \text { Backpack } \\
\text { 4. } & \text { Shoulders Back } \\
\text { 5. } & \text { Shoulders Middle }\end{array}$ & $\begin{array}{ll}\text { 1. } & \text { Helmet } \\
\text { 2. } & \text { Shoulders Middle } \\
\text { 3. } & \text { Forearms } \\
\text { 4. } & \text { Backpack } \\
\text { 5. } & \text { Shoulders Back }\end{array}$ \\
\hline Pristina & $\begin{array}{ll}\text { 1. } & \text { Helmet } \\
\text { 2. } & \text { Backpack } \\
\text { 3. } & \text { Forearms } \\
\text { 4. } & \text { Shoulders Middle } \\
\text { 5. } & \text { Shoulders Back }\end{array}$ & $\begin{array}{ll}\text { 1. } & \text { Helmet } \\
\text { 2. } & \text { Forearms } \\
\text { 3. } & \text { Backpack } \\
\text { 4. } & \text { Shoulders Back } \\
\text { 5. } & \text { Shoulders Middle }\end{array}$ & $\begin{array}{ll}\text { 1. } & \text { Helmet } \\
\text { 2. } & \text { Shoulders Middle } \\
\text { 3. } & \text { Forearms } \\
\text { 4. } & \text { Backpack } \\
\text { 5. } & \text { Shoulders Back }\end{array}$ \\
\hline
\end{tabular}

The table above indicates that the change in location or season does not affect the order in the classification immensely, although the divergence between two sensors is not constant. Hence, the classification of the sensor for each scene can be simplified to the following (Table 5):

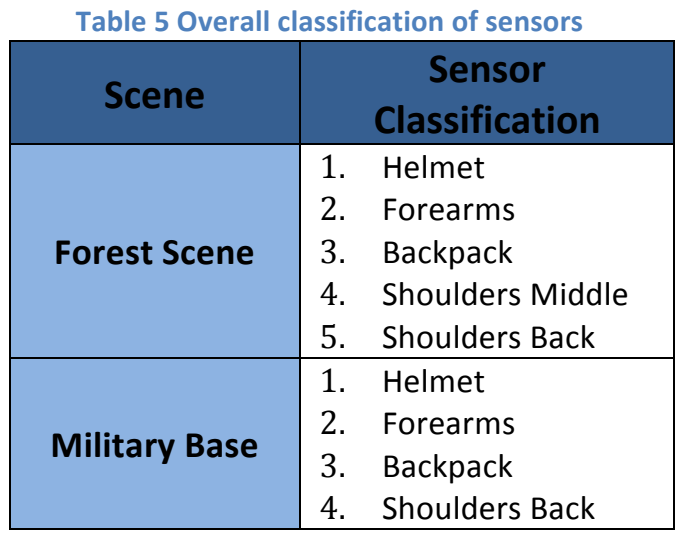




\begin{tabular}{|l|ll|}
\hline & 5. & Shoulders Middle \\
\hline & 1. & Helmet \\
& 2. & Shoulders Middle \\
Urban Area & 3. & Forearms \\
& 4. & Backpack \\
& 5. & Shoulders Back \\
\hline
\end{tabular}

Table 4 indicate that the optimum position for the integration of the PIPV on the soldier's uniform is the helmet. One can clearly see that in all locations, scenes and seasons the helmet sensor consistently yields the highest values. It is also interesting to note that the main changes in the classification of the sensors are according to location and scene but not season. More precisely we can see that the forearm is the second best location for the positioning of PIPV for the scenarios in the forest and military base scenes in Bagdad and Catterick Garrison as well as the military base in Pristina. However this is not the case for the scenario of the urban scene across each location, where the middle shoulder sensor yields the second highest value. As depicted in the table, the backpack sensor yields the third highest values for the majority of scenarios, such as those of the forest scene and military base in Bagdad, Catterick Garrison and Pristina. There are a few differences such as in the scenario of the forest scene in Pristina and the scenario of the urban area across all locations, where the forearm sensor comes third. We can also ascertain that the shoulder back sensor is the least optimum sensor for the integration of PIPV as it yields the lowest light values for the vast majority of scenarios and in contrast to other sensors.

\section{Discussion and Guidelines}

As stated in the Introduction, the usability of the PV device proposed by the Solar Soldier project is examined by liaising and interacting with the ITDU of DSTL. This interaction produced 
a preliminary set of guidelines for the integration of PV on the uniform or equipment. The feedback we received from the ITDU was invaluable, providing very important details and patterns of the soldiers' habits. This enabled us to narrow down the potential areas where PIPV could be integrated and thus reduced the number of light sensors to use in our simulations. For instance, it was gathered that the chest and the back of the uniform areas would not constitute good candidate areas for installation of PIPVs as they are constantly occluded by the gun and hands holding it and by the backpack respectively. The second set of guidelines derived from the case studies of the three different environments presented above. The overall classification of the lightmeter sensors presented in Table 5 can operate as a draft guideline for designers and manufacturers of wearable PVs in military applications. It is clearly shown that this classification can provide guides for the positioning of such devices on the uniform and equipment of the infantry soldier for the examined areas. For instance, the helmet would be the first choice for every case and environment. This fact was more or less predictable yet not validated by any study so far, as hitherto there was no other study simulating the incident light on mobile light sensors in a dynamic manner. Moving on, we notice that the forearms come in second place for the two out of three case studies and qualify as an important candidate for integration. Similarly, the top of the backpack is in the third place and again constitutes as a good candidate area of installation. The middle and back parts of the shoulder come low in most classifications and therefore should only be considered as secondary solutions and in cases of multiple PVs installed. The only environment where the middle shoulder sensors classified second was the Urban Area scene and thus it can be considered as a good universal solution but only in such an environment. Lastly, the back shoulder area is considered as not a 
very good option for installation of PIPVs as it illustrates poor performance in all environments. It is interesting to note that the forearm sensors performed well and classified in the second place in environments where there is no or little building construction, such as in a forest or military base. In environments with a denser building construction, such as the urban area, the middle shoulder sensor precedes the forearm offering a higher exposure to light energy source.

Combining the simulation data presented in this paper along with the feedback on the HCD ascertained from the ITDU we can provide the following set of guidelines and recommendations with regards to the integration of PIPVs on the modern infantry soldier:

1. The best places on the soldier's uniform in terms of ergonomics and exposure to light energy are the helmet followed by the forearm and backpack. These three positions will provide the PV system with constant exposure to solar radiation, which can be converted to energy even when the soldier is on the move.

2. It is recommended that the entire back-pack is covered with PVs as, on one hand, more PV panels can be placed and thus more energy can be harvested. On the other hand it can supply the PV system with constant energy, especially when the soldier is in the shade or resting (s)he can easily leave the back-pack in the sun. Although the helmet yields the highest amount of light its consistent supply of power to the solar harvesting system may be stopped in certain cases. In very warm environments of operations the soldier will seek shade under natural and man-made constructions such as trees and buildings and may even take off the helmet whilst resting. This necessitates further the need to place PVs on the back pack as it can be removed and placed under the sun. 
3. Integrating PV directly into the uniform is not recommended as this is washed in extremely hot water. As fabric and nano-material technology evolves it may be able to interweave the solar panel nano-material onto the uniform that will withstand extremely high temperatures. Until then it is recommended that the solar panels are attached onto Velcros so that the PV can be attached and detached. This would also enable the interchange of the PV positioning on the uniform according to the environment and location of operation. It should be noted that the issue of health risk from material transfer from a potential bullet hit through the PV is beyond the scope of this paper and project.

\section{Conclusions and Future Work}

Infantry soldiers today carry around a lot of electronic equipment which have high power consumption requirements. This forces them to carry, in dismounted operations, several heavy and bulky batteries which increase dramatically their total equipment load. Renewable energy technology such as the incorporation of PVs can substitute batteries and relieve the soldier from the physical and cognitive load. This study has proposed a virtual simulation framework that mimics closely the military environment for the purposes of investigating the integration of PIPV technology on the infantry soldier, by analysing and measuring the effectiveness of light capture on various areas of the uniform and equipment of the soldier. The examined case studies covered several basic military environments as well as the several potential areas of integration of the PV device after interacting with the army. After simulations had been performed, the resulting data were organised and presented in such a manner enabling the classification of the examined areas (light sensors) in order of light capturing efficiency. The 
three examined environments offered varying results yet some guidelines were inferred from the investigated areas. Some areas demonstrated independence from the environment (i.e. helmet) whilst other areas showed poor performance to some environments and better to others (i.e. middle shoulder area). Nevertheless, the derived overall classifications infer draft yet qualitative guidelines for any designer or practitioner of wearable Photovoltaic technology for defence applications.

With regards to the future work of this project, the first step will be the extension of the range of examined scenarios. More global locations of military interest would be examined with different environment models, covering more of the actual military missions. Furthermore, we would be investigating more soldier motion patterns for to address the effect that different types of movement has on light harvesting for the integrated PV device. Finally, as the procedures of manipulating the 3D assets and simulation adjustments require high level of expertise in 3D authoring software such as 3DSMD, we have started work on semi-automating these procedures to simplify them and increase the framework usability for PV designers and engineers. The semi-automation would be enabled by the use of Maxscript, the internal programming interface of 3DSMD, and by designing a user-friendly Graphical User Interface that would semi-automate the various steps of the methodology towards the end virtual scene to be simulated.

\section{References}

1. Zyda M, From visual simulation to virtual reality to games. Computer, 38(9), 25-32. 2005

2. Jarvenpaa S, Leidner D, Teigland R, and Wasko M, MISQ Special Issue: New Ventures in Virtual Worlds, MIS Quarterly Call for Papers. 2007. 
3. Chaturvedi A, Dolk DR, Drnevich PL, Design Principles for Virtual Worlds, MIS Quarterly, 35: 3, pp.673-684, 2011.

4. Chryssolouris G, Mavrikios D, Fragos D, Karabatsou V, A virtual reality- based experimentation environment for the verification of human-related factors in assembly processes, Robotics and Computer Integrated Manufacturing, 16 pp.267-276, 2000.

5. Reece D, Movement Behaviour for Soldier Agents on a Virtual Battlefield, Presence, Vol. 12, No. 4, pp. 387-410, August 2003.

6. Yang J, Rahmatalla S, Marler T, Abdel-Malek K, Harrison C, Validation of Predicted Posture for the Virtual Human Santos ${ }^{\mathrm{TM}}$, Digital Human Modelling, HCII 2007, LNCS 4561, pp. 500510, 2007.

7. Abdel-Malek K, Yang J, Kim JH, Marler T, Beck S, Swan C, Frey-Law L, Mathai A, Murphy C, Rahmatallah S, Aror, J, Development of the Virtual-Human SantosTM, Digital Human Modelling, HCII 2007, LNCS 4561, pp. 490-499, 2007.

8. Shiau YH and Liang SJ, Real-time network virtual military simulation system. In IV '07. 11th International Conference Information Visualization, pages 807-812, 4-6 July 2007.

9. Blount EM, Ringleb SI, Tolk A, Bailey M, Onate JA, Incorporation of physical fitness in a tactical infantry simulation, The Journal of Defence Modelling and Simulation: Applications, Methodology, Technology September 8, 2011

10. Cioppa TM, Lucas TW, Sanchez SM, Military applications of agent-based simulations. In: ed. R. G. Ingalls, M. D. Rossetti, J. S. Smith, and B. A. Peters, Proceedings of the 2004 Winter Simulation Conference, 171-180, 2004.

11. Bitinas EJ, Henscheid ZA, Truong LV, Pythagoras: A new agent-based simulation system, Technology Review Journal, pages 45-58, 2003.

12. Schmorrow D, Cohn J, Nicholson D (Editors), "The PSI Handbook of Virual Environment Training and Education: Developments for the Military and Beyond, Volume 2: VE Components and Training Technologies", Praeger Security Internastional, Westport CT, 2009.

13. Parida B, Iniyan S, Goicm R, A review of solar photovoltaic technologies, Renewable and Sustainable Energy Reviews, 15 (3): 1625-1636, 2011.

14. Chaar LE, Lamont LA, Zein NE, Review of photovoltaic technologies, Renewable and Sustainable Energy Reviews, Volume 15, Issue 5, Pages 2165-2175, June 2011.

15. Hashmi G, Miettunen K, Peltola T, Halme J, Asghar I, Aitola K, Toivola M, Lund P, Review of materials and manufacturing options for large area flexible dye solar cells, Renewable and Sustainable Energy Reviews, Volume 15, Issue 8, Pages 3717-3732, October 2011.

16. Reich NH, van Sark WGJHM, Turkenburg WC, Sinke WC, Using CAD software to simulate PV energy yield - The case of product integrated photovoltaic operated under indoor solar irradiation, Solar Energy 84 1526-1537, 2010. 
17. Mousazadeh $H$, Keyhani A, Javadi A, Mobli $H$, Abrinia $K$, Sharifi A, A review of principle and sun-tracking methods for maximizing solar systems output, Renewable and Sustainable Energy Reviews, Volume 13, Issue 8, Pages 1800-1818, October 2009.

18. Nguyen DD, Lehman B, Kamarthi S, Solar Photovoltaic Array's Shadow Evaluation Using Neural Network with On-Site Measurement, In: Electrical Power Conference, 2007. EPC 2007. IEEE Canada, vol., no., pp.44-49, 25-26 Oct. 2007.

19. Cortez L, Cortez JI, Adorno A, Muñoz-Hernandez GA, Cortez E, Study of the effects of random changes of solar radiation on energy production in a photovoltaic solar module, Canadian Journal on Electrical and Electronics Engineering Vol. 1, No. 4, June 2010.

20. Paraskevopoulos I, Tsekleves E., Simulation of Photovoltaics for Defence and Commercial Applications by Extending Existing 3D Authoring Software - A Validation Study. In: International Conference on Simulation and Modelling Methodologies, Technologies and Applications (SIMULTECH). Netherlands, 28-31 July 2011

21. Reinhart C, Breton PF, National Research Council Canada, Institute for Research in Construction, Ottawa, Canada (2001-2008), Harvard University, Graduate School of Design, Cambridge, MA, USA, Autodesk Canada, Media \& Entertainment, Montreal, Canada, 2009, Experimental Validation of 3DS Max ${ }^{\circledR}$ Design 2009 and DAYSIM 3.0, Building Simulation.

22. Reinders A, A design method to assess the accessibility of light on PV cells in an arbitrary geometry by means of ambient occlusion, In: Proceedings of 22nd EU Photovoltaic Solar Energy Conference and Exhibition, Milan, 2007.

23. Mestre A, Diehl JC, Ecodesign and Renewable Energy: How to Integrate Renewable Energy Technologies into Consumer Products, In: Environmentally Conscious Design and Inverse Manufacturing, 2005. Eco Design 2005. Fourth International Symposium on , vol., no., pp.282-288, 12-14 Dec. 2005

24. Reinders AHME, Options for photovoltaic solar energy systems in portable products, In: Proceedings of TMCE, Wuhan, China, 2002.

25. Randall J, Bharatula N, Perera N, Von Buren T, Ossevoort S, Troster G, Indoor Tracking using Solar Cell Powered System: Interpolation of Irradiance. In: International Conference on Ubiquitous Computing. 2004.

26. Schubert MB, Werner JH, Flexible solar cells for clothing, Materials Today, Volume 9, Issue 6, June 2006.

27. Bruzzone AG, Critical issues in advancing Modelling and Simulation. In: Keynote speaker: International Conference on Simulation and Modelling Methodologies, Technologies and Applications (SIMULTECH). Netherlands, 28-31 July 2011

28. Darula S and Kittler R, CIE General Sky Standard Defining Luminance Distributions. In: Proceedings eSim, 2002. 
29. Perez $R$, Seals $R$, Ineichen $P$, Stewart $R$, Menicucci $D, A$ new simplified version of the Perez diffuse irradiance model for tilted surfaces, Solar Energy, Volume 39, Issue 3, Pages 221231, 1987.

30. Autodesk (2009). (1) Daylight Simulation in 3ds Max Design 2009 - Getting Started, Retrieved January 2010 from http://images.autodesk.com/adsk/files/3dsmax_started.pdf

31. Autodesk (2009), (2) Daylight Simulation in 3ds Max Design 2009 - Advanced Concepts, Retrieved January 2010 from http://images.autodesk.com/adsk/files/3dsmax_advancedpdf

32. Sŭri $M$, Solar resource data and tools for an assessment of photovoltaic systems. In: JägerWaldau A. (editor), Status Report 2006, Office for Official Publications of the European Communities, Luxembourg, pp. 96-102, 2007. Data source: http://re.jrc.ec.europa.eu/pvgis/index.htm

33. Halsted CP, Brightness, Luminance and Confusion. Information display, March, 1993.

34. Donn M, Appropriate Daylight Metrics: Using Autodesk ${ }^{\circledR} 3 \mathrm{ds}$ Max $^{\circledR}$ to Measure Real Daylight Performance, Autodesk University, Retrieved January 2010 from: http://au.autodesk.com/?nd=material\&session_material_id=6333.

35. Thimijan RW, Heins RD. Photometric, radiometric and quantum light units of measure: a review of procedures for interconversion. Hort Sci, 18(6):818-22, 1983.

\section{ACKNOWLEDGEMENTS}

The Authors would like to thank EPSRC and DSTL for the funding of the Solar Soldier project. We would also like to thank all our project partners from Glasgow University, Loughborough University, Strathclyde University, Leeds University and University of Reading for their valuable contribution to our work. 


\section{Appendix}

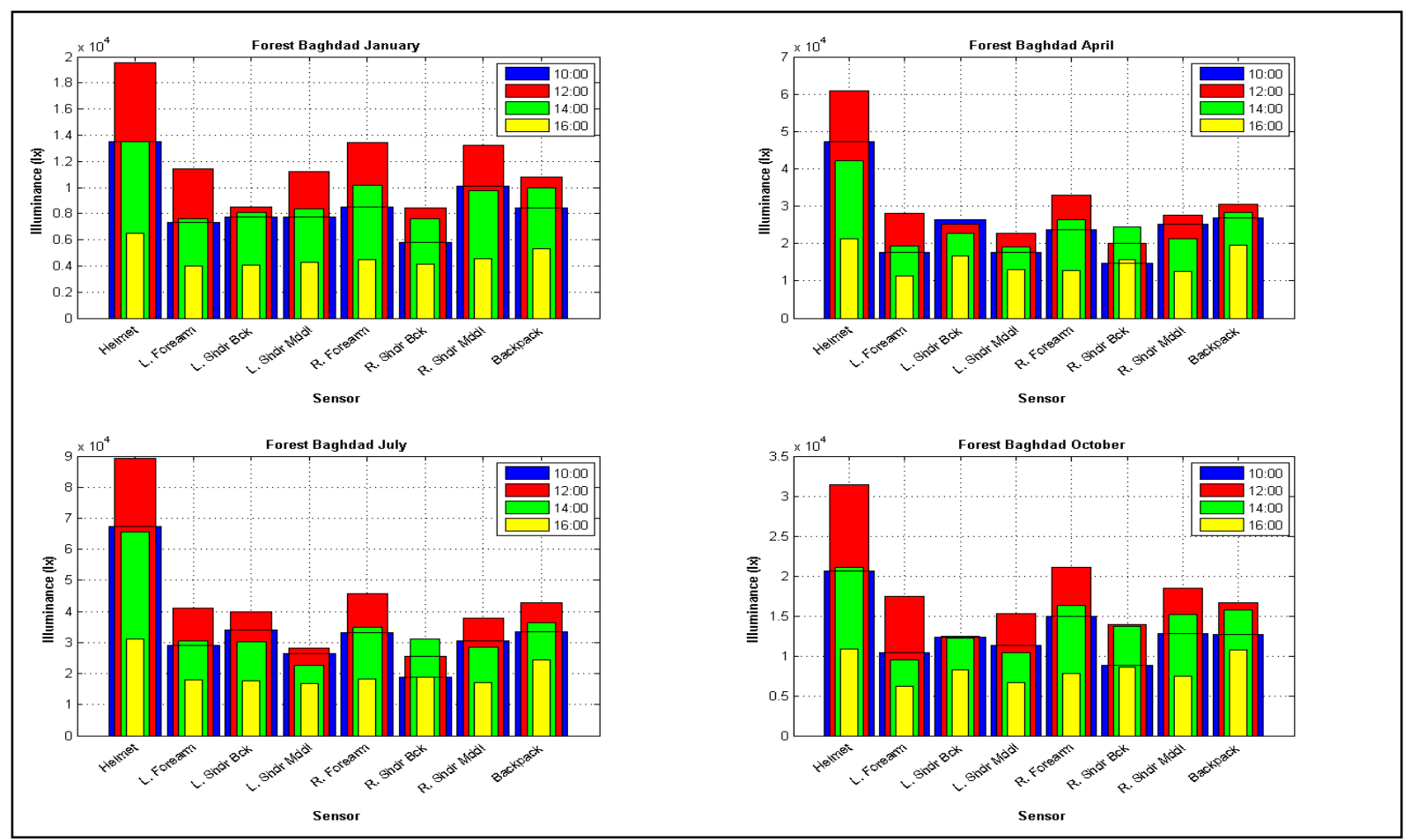

Figure 1A Forest scene in Baghdad

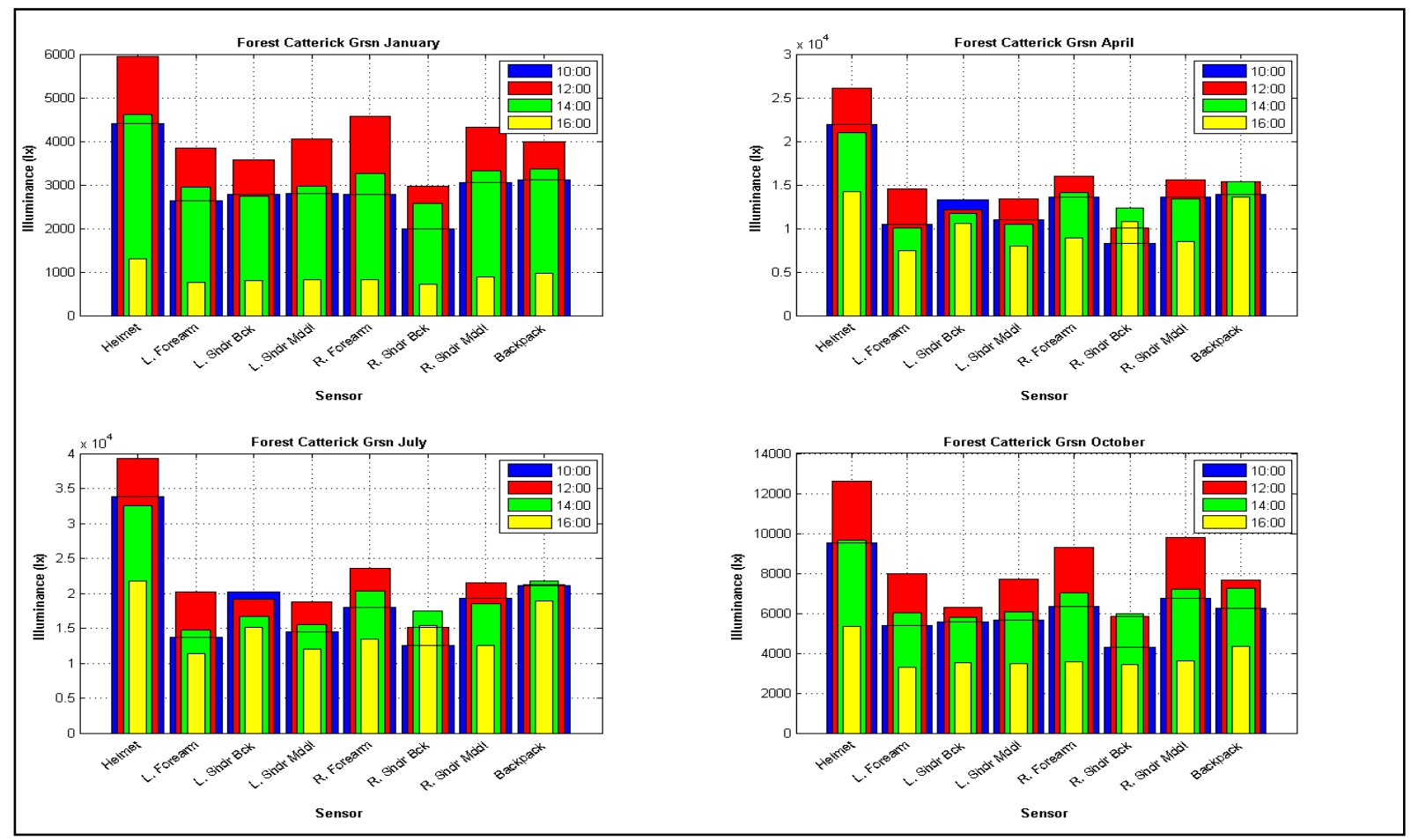

Figure 2A Forest scene in Catterick Garrison 


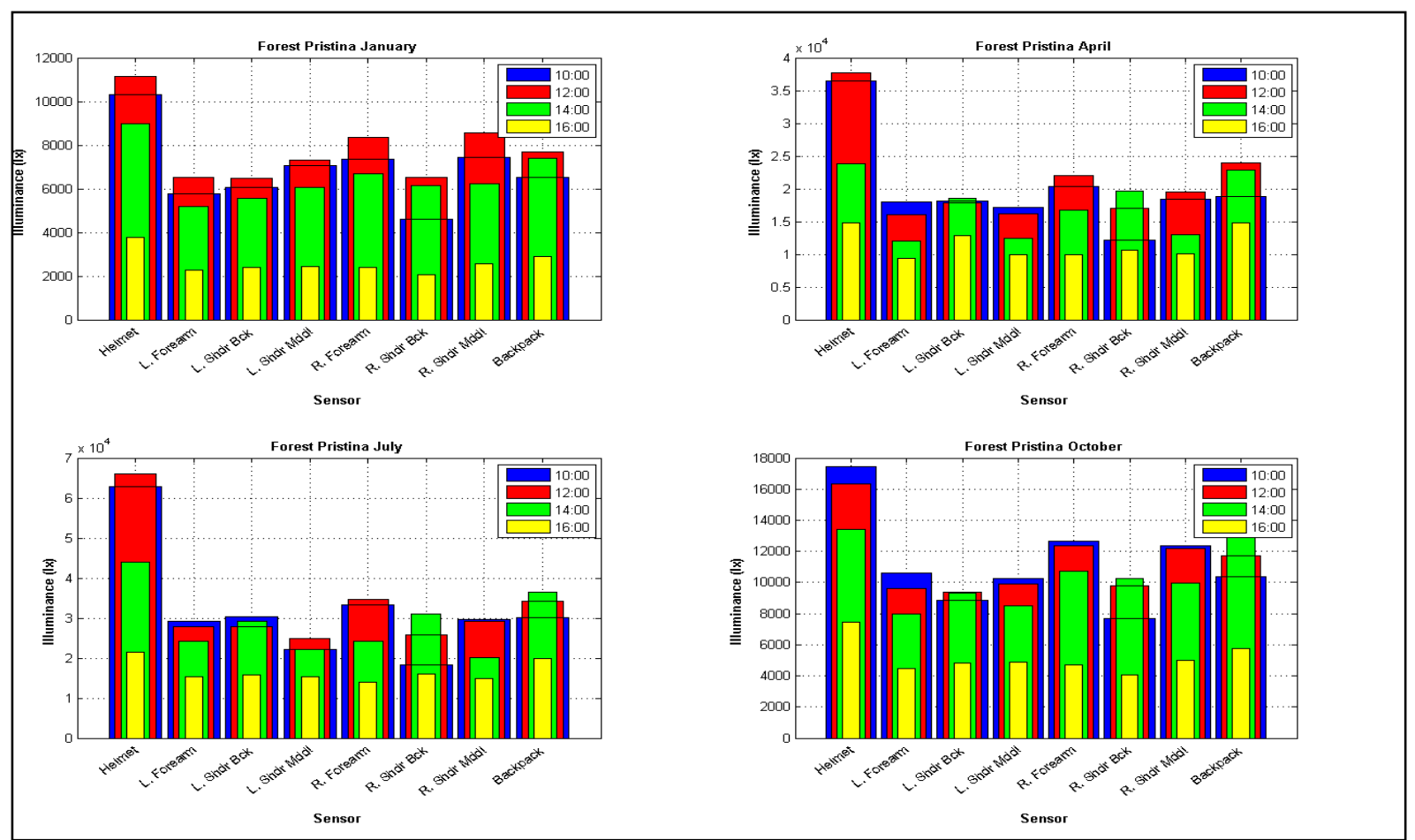

Figure 3A Forest scene in Pristina

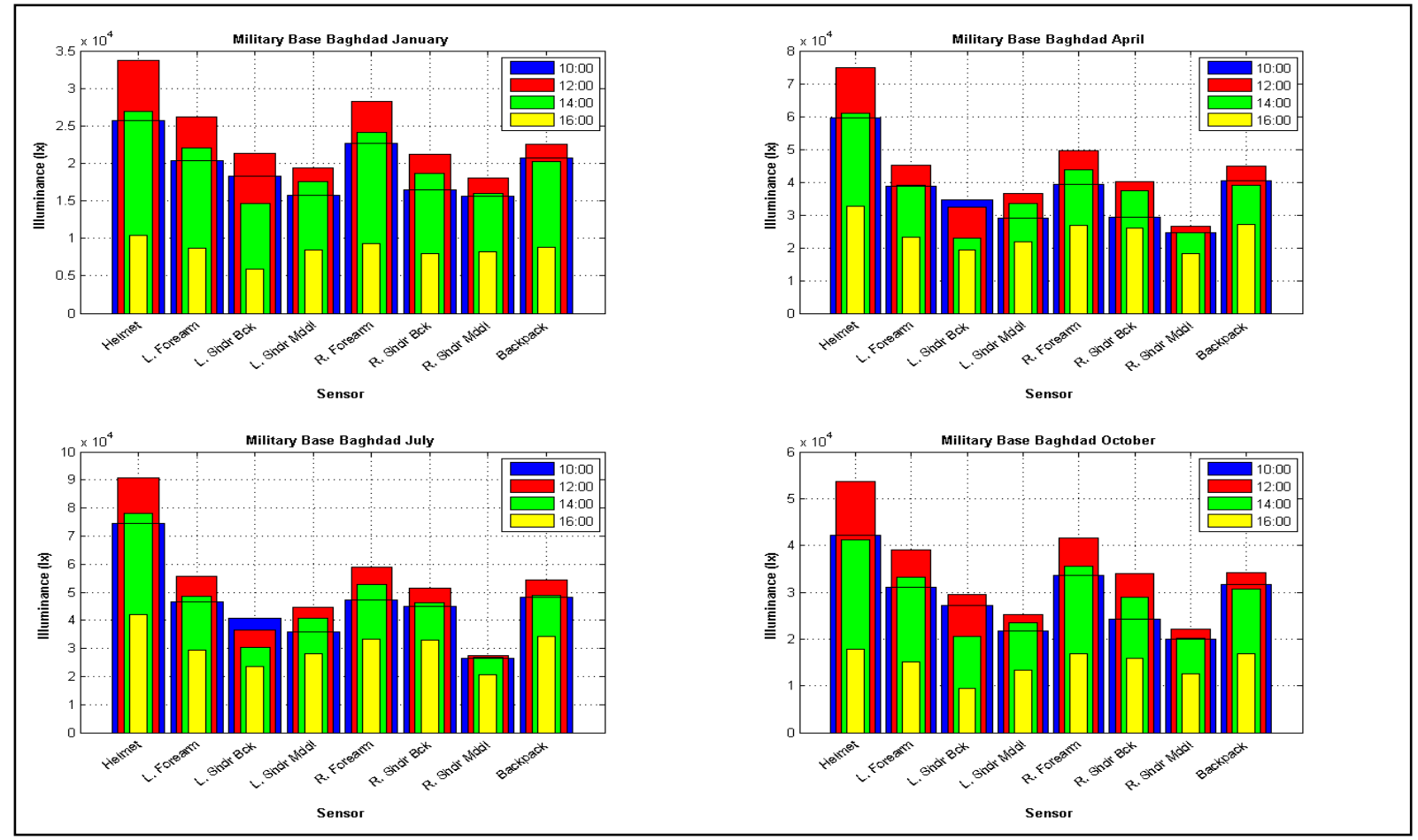

Figure 4A Military Base scene in Baghdad 


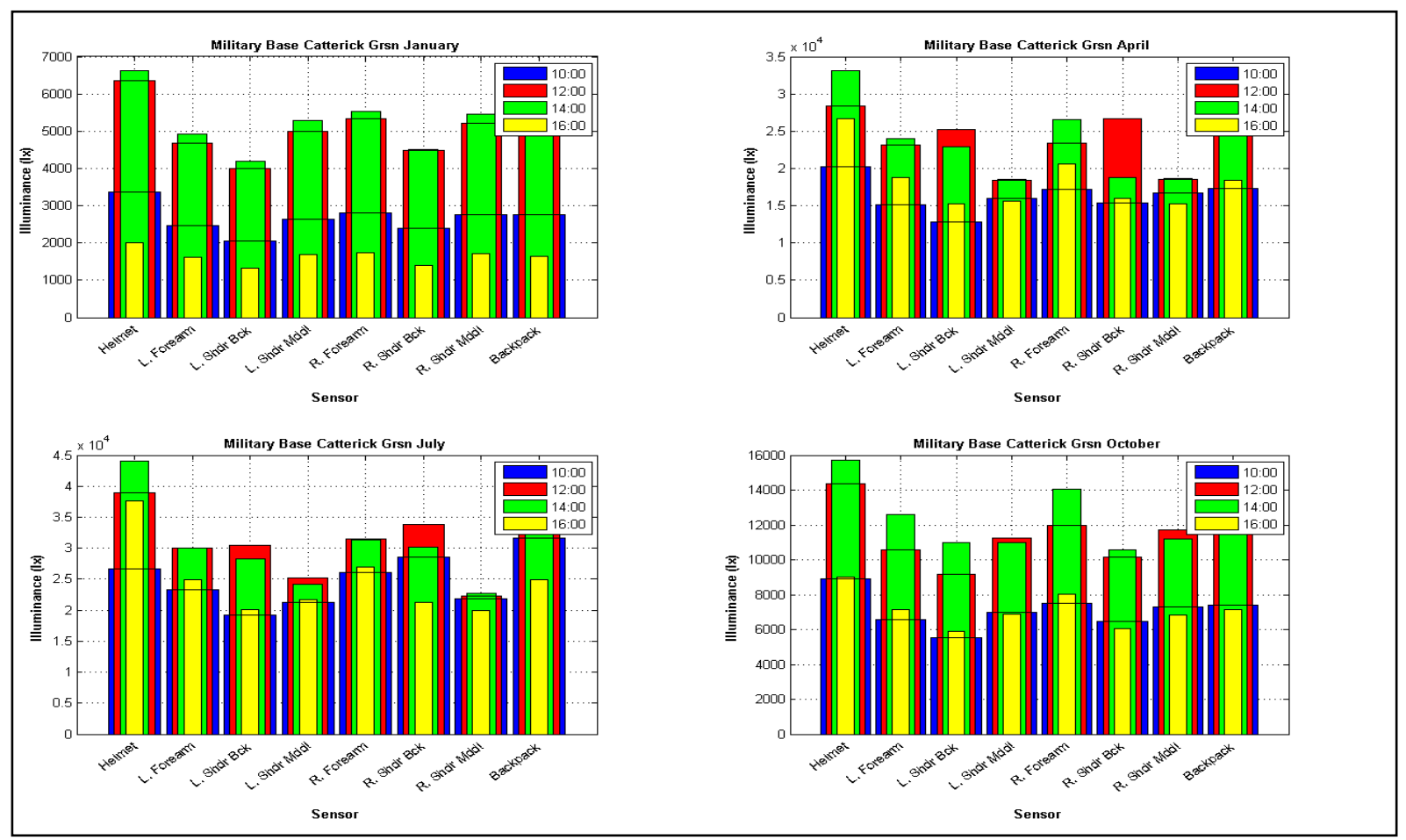

Figure 5A Military Base scene in Catterick Garrison

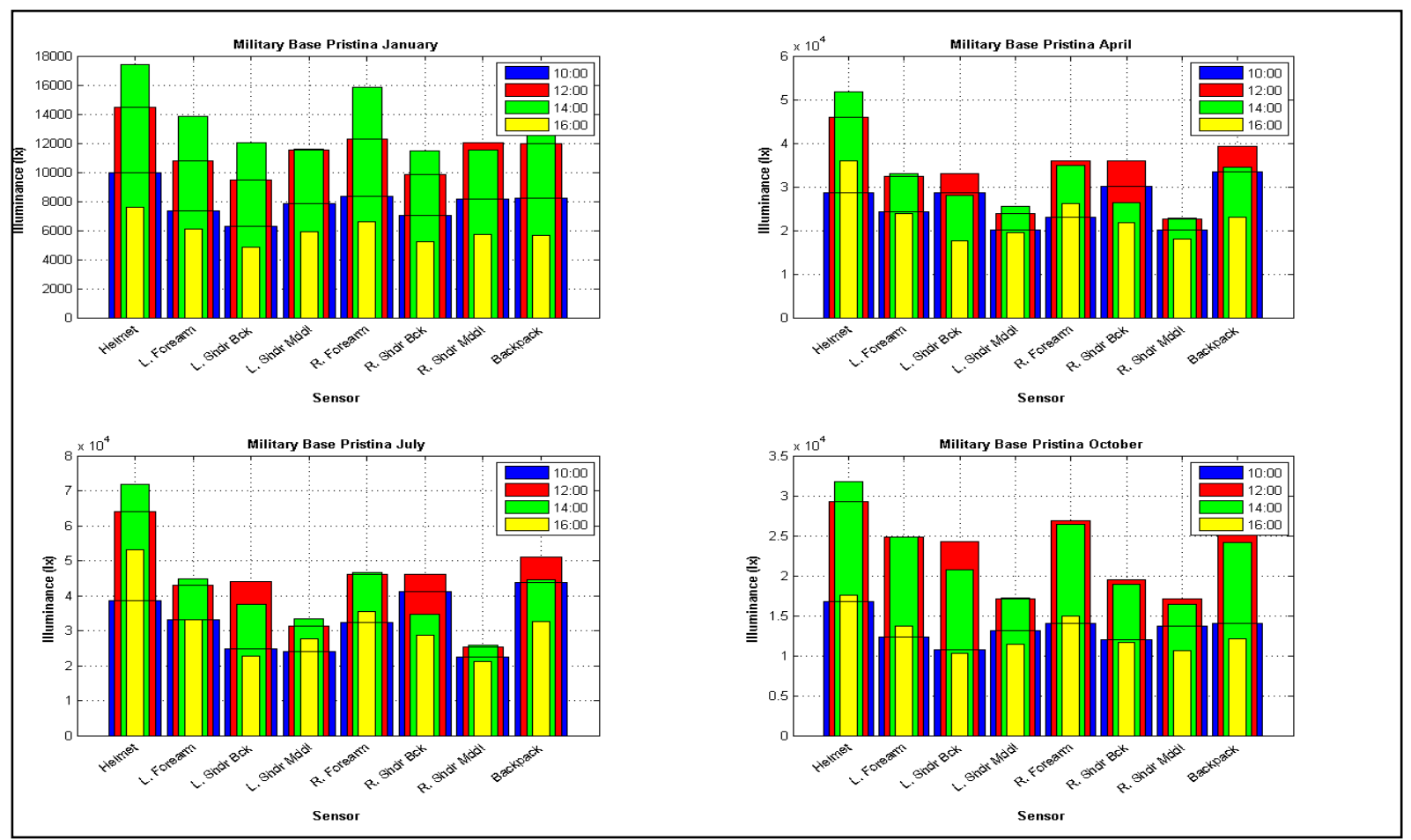

Figure 6A Military Base scene in Pristina 


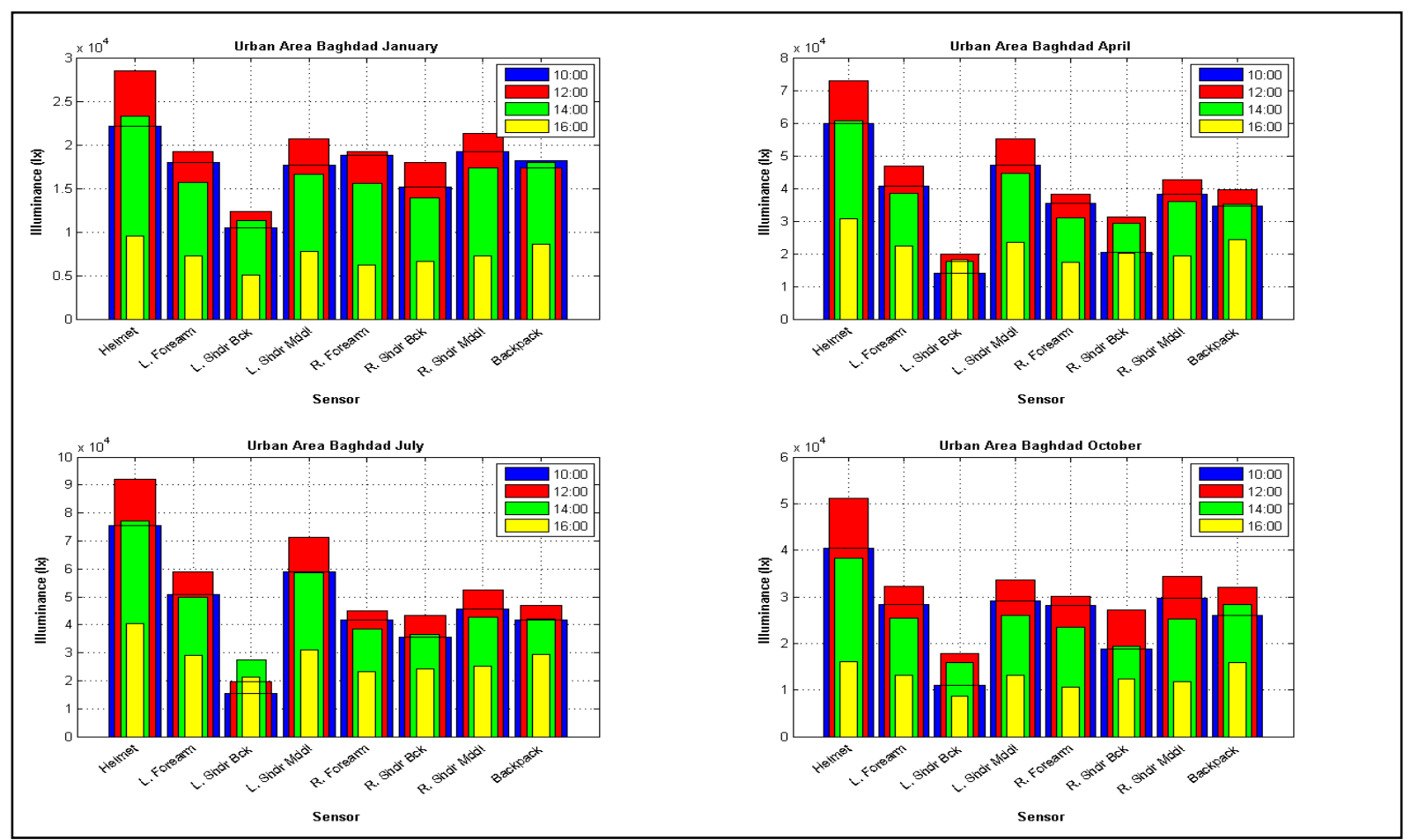

Figure 7A Urban Area scene in Baghdad
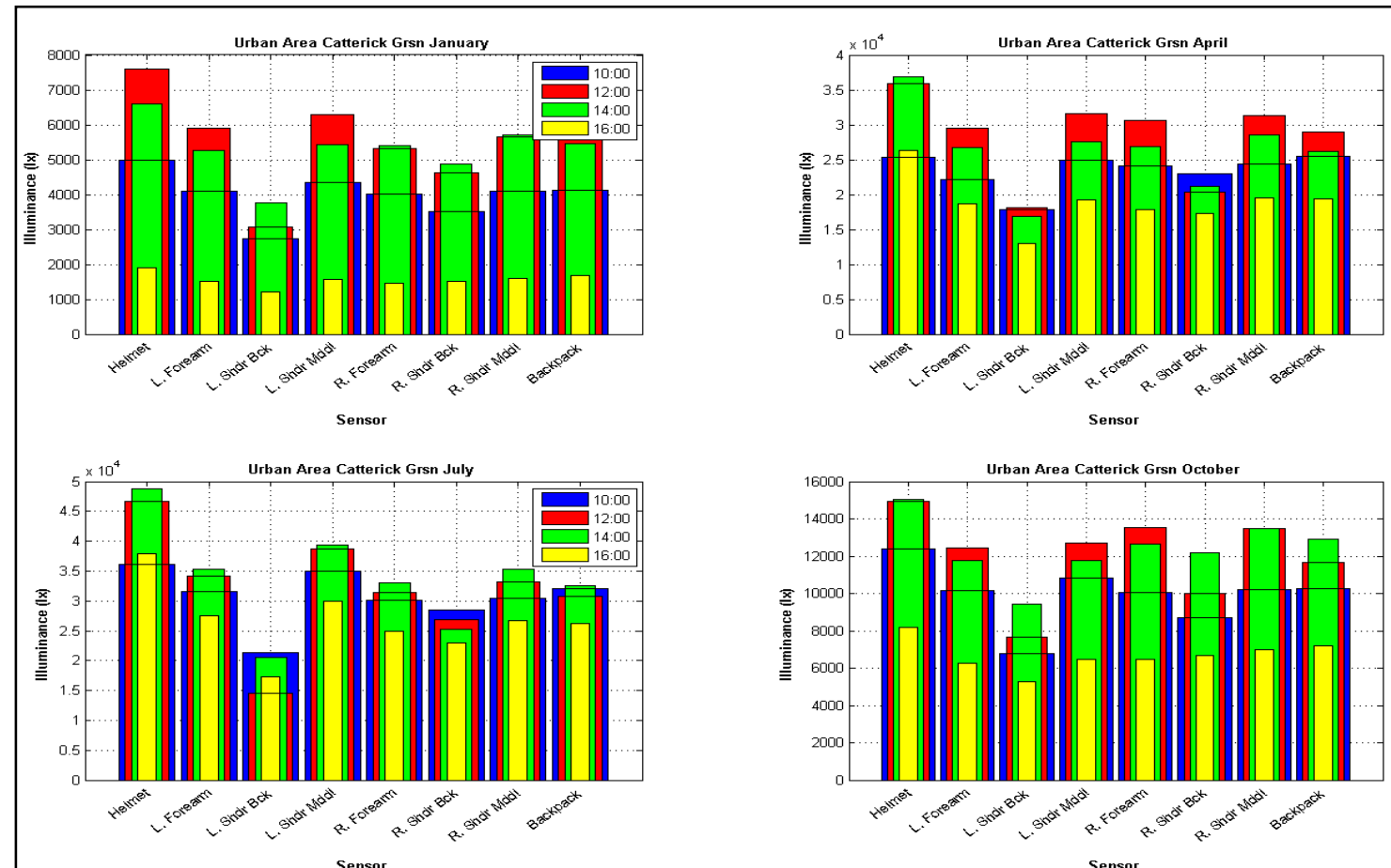

Figure 8A Urban Area scene in Catterick Garrison 


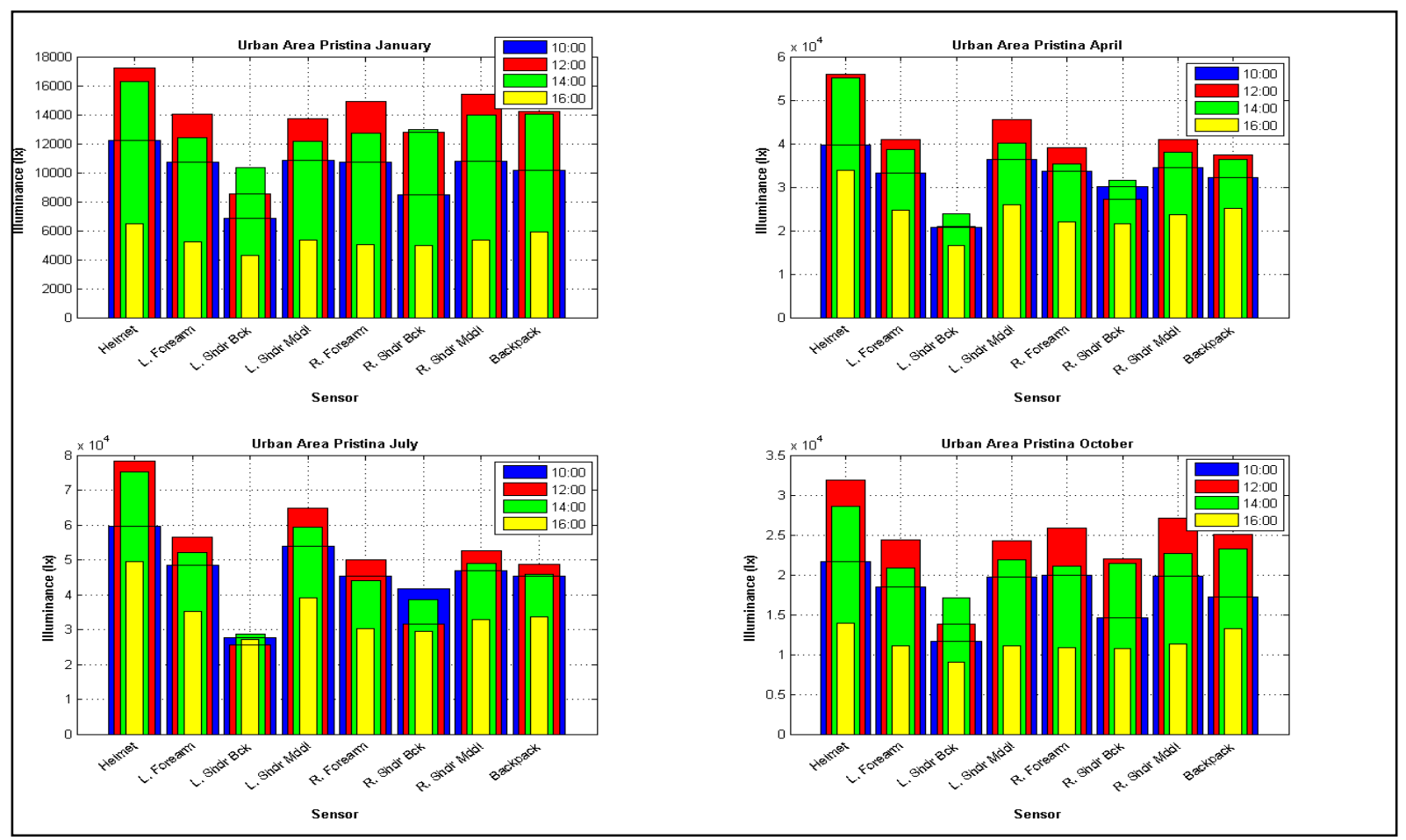

Figure 9A Urban Area scene in Pristina 